\title{
Immunogenic response induced by wzm and wzt gene deletion mutants from Brucella abortus S19
}

\author{
XIU-RAN WANG ${ }^{1-3^{*}}$, GUANG-MOU YAN ${ }^{1 *}$, RUI ZHANG $^{1,2^{*}}$, XU-LONG LANG ${ }^{2}$, YAN-LING YANG ${ }^{4}$, \\ XIAO-YAN LI ${ }^{2}$, SI CHEN ${ }^{2}$, JING QIAN ${ }^{2,3}$ and XING-LONG WANG ${ }^{1,2}$ \\ ${ }^{1}$ College of Animal Science and Veterinary Medicine, Jilin University, Changchun 130062; \\ ${ }^{2}$ Key Laboratory of Jilin Province for Zoonosis Prevention and Control, Institute of Military Veterinary, \\ AMMS, Changchun 130122; ${ }^{3}$ School of Life Science, Jilin Agricultural University, Changchun 130118; \\ ${ }^{4}$ State Key Laboratory of Special Economic Animal Molecular Biology, Institute of Special Economic Animal \\ and Plant Science, Chinese Academy of Agricultural Sciences, Changchun 130122, P.R. China
}

Received April 6, 2013; Accepted November 13, 2013

DOI: $10.3892 / \mathrm{mmr} .2013 .1810$

\begin{abstract}
Brucellosis is an infectious disease affecting humans and animals worldwide. Effective methods of control include inducing immunity in animals by vaccination and elimination. Brucella abortus S19 is one of the popular vaccines for control of cattle brucellosis, as it has low virulence. In this paper, allelic exchange plasmids of $w z m$ and $w z t$ genes were constructed and partially knocked out to evaluate the effects on the induction of immunity to Brucella abortus S19 mutants. Cytokine secretion in vitro, INF- $\gamma$ induction in vivo and antibody dynamics were evaluated. These data suggested that the immunity-eliciting ability of the wzm and wzt gene deletion mutants was similar, although reduced compared with the S19 strain. The results demonstrated that the wzt gene may be more important in the regulation of the induction of immunity than the wzm gene.
\end{abstract}

\section{Introduction}

Brucella species, the cause of brucellosis in humans and animals, are facultative intracellular bacteria. Brucella invades phagocytic and non-phagocytic cells and survives inside the host cells $(1,2)$. The properties of the intracellular lifestyle of Brucella limit the number of antibiotics that are effective against these organisms once they form Brucella-containing

Correspondence to: Professor Xing-Long Wang, Key Laboratory of Jilin Province for Zoonosis Prevention and Control, Institute of Military Veterinary, AMMS, No. 666 Liuying Road, Changchun, Jilin 130122, P.R. China

E-mail: wangxl_2006@163.com

*Contributed equally

Key words: brucellosis, ABC transporter, rough mutant, ELISA, cytokine vacuoles (BCVs) (3). Under most conditions, control of brucellosis in animal reservoirs is achieved via vaccination. Human brucellosis has also been controlled by immunization and culling within cattle, goat and sheep herds $(4,5)$.

Currently there are no vaccines for humans and the useful vaccines for livestock are (Brucella abortus) B. abortus S19 and RB51 for cattle and Brucella melitensis (B. melitensis) Rev1 for small ruminants $(6,7)$. B. abortus $\mathrm{S} 19$ has been widely used to prevent cattle brucellosis, as it usually has low virulence. However, it is infectious in humans and always causes abortion when used in pregnant animals $(8,9)$. Since B. abortus S19 induces antibodies to the O-polysaccharide, it is difficult to distinguish from wild-type infection. The relevant diagnostic antigen is the smooth lipopolysaccharide (LPS) present in field strains, as well as in B. abortus S19 and B. melitensis Rev 1 (10-12). The development of a safe and efficacious vaccine that conquers this serological obstacle may have a broad impact on public health.

LPS provides bacterial resistance to antimicrobial attacks and modulates the host immune response, which makes it an important virulence factor for survival and replication in the host cell $(1,13)$. It provides Brucella with resistance to innate immunity antibacterial responses by inhibiting complement and antibacterial peptide attacks, and by preventing the synthesis of immune mediators (14-16). The O-chain appears to help Brucella to invade cells in the early entry stage (17).

Brucellae without $\mathrm{O}$-side chains are termed as rough or ' $\mathrm{R}$ ' strain. R Brucella species or mutants lack the antigenic O-side chain and they do not induce anti-O-side chain antibodies. Currently, vaccinated hosts are difficult to distinguish from wild-type-infected hosts by common serological tests. It has been shown that Brucella $\mathrm{R}$ mutants are attenuated; therefore, $\mathrm{R}$ mutants have potential for use as vaccines (18-22). Several genes of $B$. melitensis $16 \mathrm{M}$ LPS synthesis were analyzed and ABC-type transporter (integral membrane protein, Wzm) and ABC-type transporter (ATPase domain, Wzt) were determined to be putative components of the ABC transporter system. The wzm/wzt mutant was proven to lead to the absence of the O-side-chain on the bacterial surface $(23,24)$. 
The wzt mutant of $B$. melitensis $16 \mathrm{M}$ was evaluated and determined to have virulence-reducing potential in a mouse model (25). In recent years, LPS has been shown to interfere with major histocompatibility complex (MHC)-II presentation, which inhibits peptide presentation in cells $(13,16)$. In the present study, we constructed $w z m$ and $w z t$ gene partial deletion mutants with no DNA marker addition, in order to estimate the survival in vivo and the serological response. This may provide us with an improved understanding of the effect of $w z m$ and wzt genes on the induction of immunity caused by the S19 vaccine strain.

\section{Materials and methods}

Bacterial strains and growth conditions. Escherichia coli DH5 $\alpha$ strain was grown on Luria-Bertani broth (LB) agar at $37^{\circ} \mathrm{C}$. Brucella strains $B$. abortus $\mathrm{S} 19, \Delta \mathrm{wzm}$ and $\Delta \mathrm{wzt}$ were grown on tryptic soy broth (TSB, Sigma, St. Louis, MO, USA) agar at $37^{\circ} \mathrm{C}$. Ampicillin $(100 \mu \mathrm{g} / \mathrm{ml})$ and kanamycin $(50 \mu \mathrm{g} / \mathrm{ml})$ were added for plasmid screening if required. TSB medium (7\% sucrose) was prepared for screening of allelicexchange mutants.

Construction of wzt and wzm mutants. The allelic exchange plasmids were constructed by pBKCMV $\left(\operatorname{kan}^{\mathrm{r}}\right)$ with a $s a c B$ gene and fragments upstream and downstream of target genes. The $s a c B$ gene along with its promoter was amplified from pIBP279 (provided by Nanjing Agricultural University) using PCR methods and ligated into $p B K s a c B$ to construct pBKsacBwzm and pBKsacBwzt (Table I). Competent cells of B. abortus S19 were prepared and the constructed plasmid was electroporated into the cells at $1,500 \mathrm{kV}[1-\mathrm{mm}$ gap cuvette; BTX, Harvard Apparatus, Inc, Holliston, MA, USA]. Subsequently, $1 \mathrm{ml} \mathrm{SOC} \mathrm{(2 \%} \mathrm{tryptone,} 0.5 \%$ yeast extract, $10 \mathrm{mM} \mathrm{NaCl}, 2.5 \mathrm{mM} \mathrm{KCl}, 10 \mathrm{mM} \mathrm{CaCl}_{2}, 10 \mathrm{mM} \mathrm{MgSO}_{4}$ and $20 \mathrm{mM}$ glucose) was added and cells were grown under agitation at $28^{\circ} \mathrm{C}$ for $24 \mathrm{~h}$ and then plated on TSB agar $\left(\operatorname{kan}^{\mathrm{r}}\right)$ and cultured for $96 \mathrm{~h}$ at $28^{\circ} \mathrm{C}$. The mutants were confirmed using PCR. The phenotype of the mutants was then determined by agglutination with acriflavine at a dilution of 1:100 (26).

Animals. The 4-6-week-old female specific pathogen-free (SPF) BALB/c mice were provided by the animal centre of Jilin University (Changchun, China). Mice were bred in the animal facilities with filtered air in a restricted-access room and under pathogen-limited conditions. Mice were acclimatised for a minimum of one week prior to the experiment and water and food was provided ad libitum. The animal experiments were approved by the Center of Laboratory Animals, Jilin University, China.

Serological test and antibody dynamics. Female BALB/c mice of 6-8 weeks of age were housed with water and food. Animals were randomly allocated to groups and acclimatised for 1 week prior to the initiation of experiments $(n=5)$. To prepare the inoculated samples, bacteria were suspended in PBS and adjusted to the appropriate $10^{8} \mathrm{CFU} / \mathrm{ml}$ in the same buffer. Blood samples from BALB/c mice were collected and allowed to clot for $12 \mathrm{~h}$ at $4^{\circ} \mathrm{C}$ and centrifuged. Serum was divided into Eppendorf tubes (Eppendorf, Hamburg,
Table I. Bacteria and plasmids.

\begin{tabular}{|c|c|c|}
\hline $\begin{array}{l}\text { Strain or } \\
\text { plasmid }\end{array}$ & $\begin{array}{c}\text { Phenotype } \\
\text { and/or genotype }\end{array}$ & Source \\
\hline \multicolumn{3}{|l|}{ Strains } \\
\hline B. abortus S19 & Vaccine strain, smooth & IVDC \\
\hline B. abortus $\Delta w z m$ & B. abortus S19 $\Delta w z m$ & This study \\
\hline B. abortus $\Delta w z t$ & B. abortus S19 $\Delta w z t$ & This study \\
\hline \multicolumn{3}{|l|}{ Plasmid } \\
\hline pBKCMV & Kanamycin & Stratagene \\
\hline pIBP279 & With $s a c B$ gene & NJAU \\
\hline
\end{tabular}

IVDC, China Institute of Veterinary Drug Control, Beijing, China; NJAU, Nanjing Agricultural University, Nanjing, China.

Germany), and stored at $-80^{\circ} \mathrm{C}$. The Rose Bengal plate agglutination test (RBPT, Harbin Pharmaceutical Group Bio-vaccine Co., Harbin, China) was carried out by mixing $30 \mu \mathrm{l}$ serum and $30 \mu \mathrm{l}$ antigen, and the reaction was observed after $4 \mathrm{~min}$.

The IgG antibody titer was estimated by indirect enzyme-linked immunosorbent assay (ELISA). The 96-well plates were coated by diluted Brucella antigens S19, $\Delta w z m$ and $\Delta w z t(\mathrm{pH} 9.6,0.05 \mathrm{M}$ carbonate buffer $100 \mu 1$ each well, antigen concentration $10^{8} \mathrm{pfu}$ ), at $4^{\circ} \mathrm{C}$ overnight. The plate was washed with $200 \mu 1$ PBST buffer ( $\mathrm{pH} 7.4,0.01$ M PBS: Tween-20, 1:1,000) three times, for 3 min each time, and then blocked by $100 \mu 11 \% \mathrm{BSA}(\mathrm{pH} 7.4)$ and incubated at $37^{\circ} \mathrm{C}$ for $1 \mathrm{~h}$ followed by three washes with PBST. The sera samples diluted from 1:100 to 1:3,200 were added and incubated at $37^{\circ} \mathrm{C}$ for $1 \mathrm{~h}$. After three washes with PBST, enzyme-labeled goat anti-mouse $\operatorname{IgG}(1: 5,000)$ was added and incubated at $37^{\circ} \mathrm{C}$ for $1 \mathrm{~h}$ and then washed with PBST three times. TMB substrate solution $(100 \mu \mathrm{l})$ was then added and incubated at $37^{\circ} \mathrm{C}$ for $10 \mathrm{~min}$ (in light). Then, $50 \mu 12 \mathrm{M}$ sulfate buffer was added to stop the reaction, followed by detection of optical density (OD) at $490 \mathrm{~nm}$. The antibody titer was described as the diluted ratio controlled by the $\mathrm{S} / \mathrm{N}$ ratio. If the $\mathrm{S} / \mathrm{N}$ ratio was $\geq 2.1$, the sample of serum was considered positive. The $\mathrm{S} / \mathrm{N}$ ratio was calculated as: (sample - blank) $\mathrm{OD}_{490} /$ (negative - blank)OD $\mathrm{OD}_{490}$.

Lymphocyte proliferation. After injecting antigens for 4 weeks, the spleens of mice were removed under sterile conditions, put in a sterile Petri dish with $4 \mathrm{ml}$ lymphocyte separation liquid (Dakewe Biotech Co., Shenzhen, China) and then ground with a disposable syringe core in a 200-mesh nylon sieve (74 $\mu \mathrm{m}$ pore diameter). The spleen cell suspension was then added to a sterile centrifuge tube and $500 \mu 1$ of RPMI-1640 medium was gradually added. The cells were then centrifuged for $10 \mathrm{~min}$ at $300 \mathrm{x} \mathrm{g}$. The lymphocyte layer was placed into new centrifuge tubes, resuspended in $10 \mathrm{ml}$ of RPMI-1640 and centrifuged for $2 \mathrm{~min}$ at $1,500 \mathrm{rpm}$. Subsequently, $5 \mathrm{ml}$ of $0.15 \mathrm{M}$ Tris- $\mathrm{NH}_{4} \mathrm{Cl}$ solution was added to the cells and the cells were centrifuged at $200 \mathrm{x} g$ for $5 \mathrm{~min}$ after $5 \mathrm{~min}$ incubation at room temperature. The supernatant was removed and the cells were washed twice with RPMI-1640. The lymphocytes were resuspended by 




Figure 1. The construction of allelic exchange plasmids, and the mutant site descriptions at Brucella abortus (B. abortus) S19 chromosome. (A) Allelic exchange diagram of constructed plasmids and chromosome of S19. (B) Constructs of B. abortus $\Delta w z m$. (C) Constructs of B. abortus $\Delta w z t$. The number is the locus of the target genes on the chromosome from NCBI.

RPMI-1640 with 5\% FBS and the cell concentration was adjusted to $2 \times 10^{6} / \mathrm{ml}$.

The lymphocytes $\left(1 \times 10^{4}\right.$ per well in triplicate) were incubated with corresponding antigens (multiplicity of infection of 200 CFU/cell; PBS in RPMI-1640 medium as negative control) in 96 -well plates at $37^{\circ} \mathrm{C}$ in an atmosphere containing $5 \%(\mathrm{v} / \mathrm{v})$ $\mathrm{CO}_{2}$. After $24 \mathrm{~h}$ of culture, $20 \mu \mathrm{l}$ MTS solution was added to each well and the cells were incubated for $4 \mathrm{~h}$ at $37^{\circ} \mathrm{C}$ in an atmosphere containing 5\% (v/v) $\mathrm{CO}_{2}$. The absorbance (optical density, OD) at $490 \mathrm{~nm}$ was recorded. Lymphocyte proliferation ratio (IS) was calculated as: $\left(\mathrm{OD}-\mathrm{OD}_{1640}\right) /\left(\mathrm{OD}_{\mathrm{PBS}^{-}} \mathrm{OD}_{1640}\right)$.

Cytokine induction in vitro and in vivo. The lymphocyte cells $\left(1 \times 10^{5}\right.$ per well in triplicate) were incubated with corresponding antigens (multiplicity of infection of $200 \mathrm{CFU} / \mathrm{cell}$; PBS in RPMI-1640 as negative control) for $24 \mathrm{~h}$ in 24-well plates at $37^{\circ} \mathrm{C}$ in an atmosphere containing $5 \%(\mathrm{v} / \mathrm{v}) \mathrm{CO}_{2}$. The cell culture supernatants were collected and stored at $-80^{\circ} \mathrm{C}$. The cytokine levels were analyzed using R\&D Quantikine TNF- $\alpha$, INF- $\gamma$, IL-2, IL-4 and IL-10 kits according to the manufacturer's instructions (Minneapolis, MN, USA). The INF- $\gamma$ levels of serum were estimated using the same method.

Statistical analysis. The data were analyzed using Original 7.5 software and presented as the means \pm standard deviation (mean $\pm \mathrm{SD}$ ). Significant differences between the groups were identified by one-way ANOVA (significant difference, $\mathrm{P}<0.01$ and $\mathrm{P}<0.05$ ).

\section{Results}

Screening of mutant strains. In order to obtain partial mutants of wzm and wzt genes, the plasmids pBKsacBwzm and pBKsacBwzt were constructed as shown in Fig. 1A-C. The plasmid was then electroporated into B. abortus S19 cells. The transformed samples were plated on TSB agar medium $\left(\operatorname{Kan}^{r}\right)$ for the first screen. The colonies were added to TSB medium and detected by PCR with $s a c B$ primers for
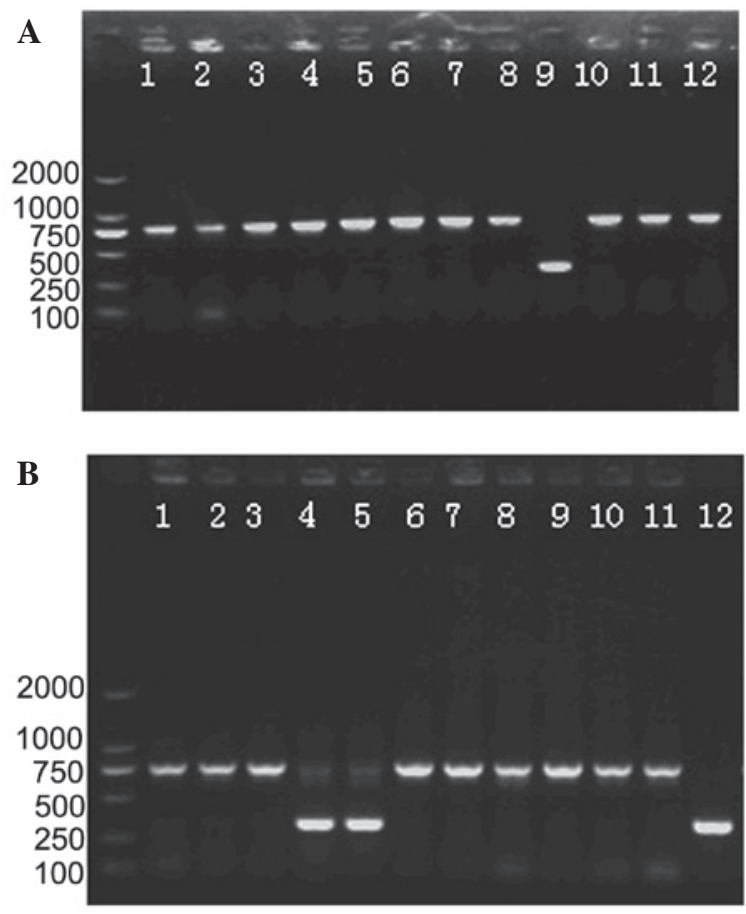

Figure 2. PCR detection of mutants. (A) The results of the fourth screen of $\Delta w z m$. Lane 6 is the false positive mutant and lane 9 is the putative positive mutant. (B) The results of the fourth screen of $\Delta w z t$. Lanes 4 and 5 are false positive mutants, and lane 12 is the putative positive mutant.

the second screen. The positive culture was spread on $7 \%$ sucrose TSA medium for the allelic exchange screen (27). The colonies from 7\% sucrose TSB agar medium were inoculated into TSB medium and screened by pre-gene primers ( $w z m$ or $w z t$ gene) for the fourth screen. If the cells were mutants, the target gene was found to be shorter than the pre-gene. The positive mutants were those with only one band $\sim 300$ bp after the screening process (Fig. 2). The putative-positive mutants were inoculated into TSB medium $\left(\mathrm{Kan}^{\mathrm{r}}\right)$ to remove the false-positive mutants. 


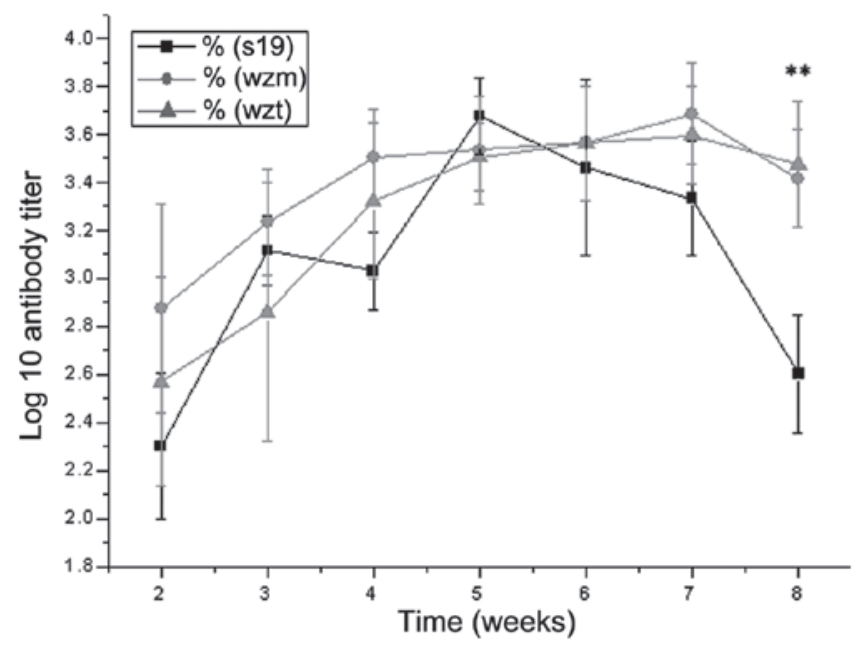

Figure 3. Antibody dynamic of positive control (S19), $\Delta w z m$ and $\Delta w z t$ mutants $(\mathrm{n}=5) .{ }^{* *} \mathrm{P}<0.01$ compared with the $\mathrm{S} 19$ group.

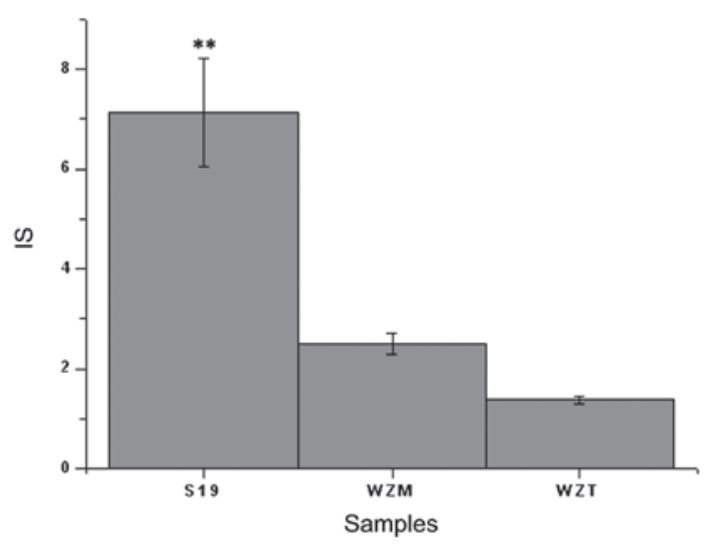

Figure 4. Lymphocyte proliferation (IS) of S19, $\Delta w z m$ and $\Delta w z t$ mutants by the MTS method $(n=5) .{ }^{* *} \mathrm{P}<0.01$ vs. the wzm and wzt groups, respectively.

Mutant strains were rough mutants. After 30 passage cultures for genetic stability, the mutants were detected by PCR using target gene primers and upstream and downstream fragment primers, and the sequences were analyzed. The mutants were prepared for acriflavine agglutination. The $\Delta w z m$ and $\Delta w z t$ mutants were positive and the S19 strain was negative for acriflavine agglutination.

The results of the Rose Bengal plate agglutination test (RBT) showed positive and negative serum for the S19 group and the $\Delta w z m$ and $\Delta w z t$ groups, respectively. Therefore, $\Delta w z m$ and $\Delta w z t$ mutants did not elicit the antibody response to $\mathrm{O}$-antigen in the host. These results indicated that the mutants were rough mutants.

Antibody dynamics. The IgG antibody changes of $\Delta w z m$ and $\Delta w z t$ mutants and S19 are shown from the second to the ninth week (Fig. 3). The antibody titer of $\Delta w z m$ induced in mice was higher than S19 strain before the fourth week and after the sixth week. Particularly at the eighth week, the $\log 10$ antibody titer of mutant strains ( $\mathrm{S} / \mathrm{N}$ value of $\Delta w z m$ and $\Delta w z t$ mutants was $3.42 \pm 0.20$ and $3.48 \pm 0.26$, respectively) was significantly higher than the $\mathrm{S} 19$ strain $(\mathrm{S} / \mathrm{N}=2.60 \pm 0.25, \mathrm{P}<0.01)$. These results indicated that the rough mutants may induce higher antibody titers than the S19 strain.

Lymphocyte proliferation. Lymphocyte proliferation is an important stage of the immune response. The results showed (Fig. 4) that the IS of S19 $(7.13 \pm 1.09)$ was significantly higher than that of $\Delta w z m(2.48 \pm 0.21)$ and $\Delta w z t(1.38 \pm 0.07)$ mutants $(\mathrm{P}<0.01)$, which indicated that $\mathrm{S} 19$ induced higher lymphocyte proliferation. The IS of the $\Delta w z m$ mutant was approximate to that of the $\Delta w z t$ mutant $(\mathrm{P}>0.05)$. The disruption of $w z m$ and wzt genes caused significantly decreased lymphocyte proliferation ability compared with the wild-type strain S19.

Cytokine secretion. The important immune-related cytokines INF- $\gamma$, IL-2, IL-4, IL-10 and TNF- $\alpha$ were detected in vitro (lymphocytes cultured in 24 -well plates). The TNF- $\alpha$, INF- $\gamma$, IL-2, IL-4 and IL-10 results showed that the cytokines induced by the $\Delta w z m$ and $\Delta w z t$ rough mutants were decreased and significantly lower than the $\mathrm{S} 19$ parent strain $(\mathrm{P}<0.01$, Fig. 5A-E). IL-4 and TNF- $\alpha$ levels induced by $\Delta w z t$ mutants were lower than those induced by $\Delta w z m$ mutants $(\mathrm{P}<0.01)$ and INF- $\gamma$, IL-10 and IL-2 levels induced by $\Delta w z t$ mutants were approximate to those induced by $\Delta w z m$ mutants $(\mathrm{P}>0.05)$.

The INF- $\gamma$ levels in serum were also detected from weeks 2 to 9. The curve (Fig. 6) showed that $\mathrm{S} 19$ and $\Delta w z m$ rough mutant induced higher INF- $\gamma$ levels $(S 19,127.6 \pm 1.1 \mathrm{pg} / \mathrm{ml}$ at the third week; $\Delta w z m$ rough mutant, $67.6 \pm 6.8 \mathrm{pg} / \mathrm{ml}$ at the fourth week), while the INF- $\gamma$ levels induced by $\Delta w z t$ rough mutants were lower than those of $\mathrm{S} 19$ and $\Delta w z m$ $(17.8 \pm 14.7 \mathrm{pg} / \mathrm{ml}$ on fourth week). The peak time of the INF- $\gamma$ induction of $\Delta w z m$ rough mutants (the fifth week was the peak of the curve) was delayed compared with S19 (peak of the curve was evident at the fourth week), and the $\Delta w z t$ rough mutants were even more delayed. The concentrations of INF- $\gamma$ induced by rough mutants were lower than those of $\mathrm{S} 19$, and the concentrations induced by $\Delta w z t$ rough mutants were the lowest.

\section{Discussion}

In the present study, knockout of wzm and wzt genes caused the rough mutant. The wzm and wzt genes are the membranespanning homologs and the ATP-binding homologs of ABC-transporters involved in transmembrane export for O-polysaccharide chain biosynthesis (28). Previous studies on $B$. melitensis $16 \mathrm{M}$ observed that the mutant of $w z m$ or $w z t$ gene was a rough mutant (23-25). The acriflavine agglutination results indicated that the $\Delta w z m$ and $\Delta w z t$ mutants were rough mutants (21). Smooth strains did not induce acriflavine agglutination, suggesting that vaccination with these mutant strains may allow for differentiation between vaccinated and wild-type smooth strain-infected animals.

The cytokine-inducing ability of rough mutants was reduced. INF- $\gamma$ is one of the most important cytokines in resistance to Brucella invasion, which enhances the macrophage bactericidal activity (29). The INF- $\gamma$ levels induced by the $\Delta w z m$ and $\Delta w z t$ rough mutants was lower than those of the smooth strain S19 in vivo although not significantly lower. By contrast, INF- $\gamma$ levels induced by the $\Delta w z m$ and $\Delta w z t$ mutants were significantly lower as compared to S19. IL-2 was detected 

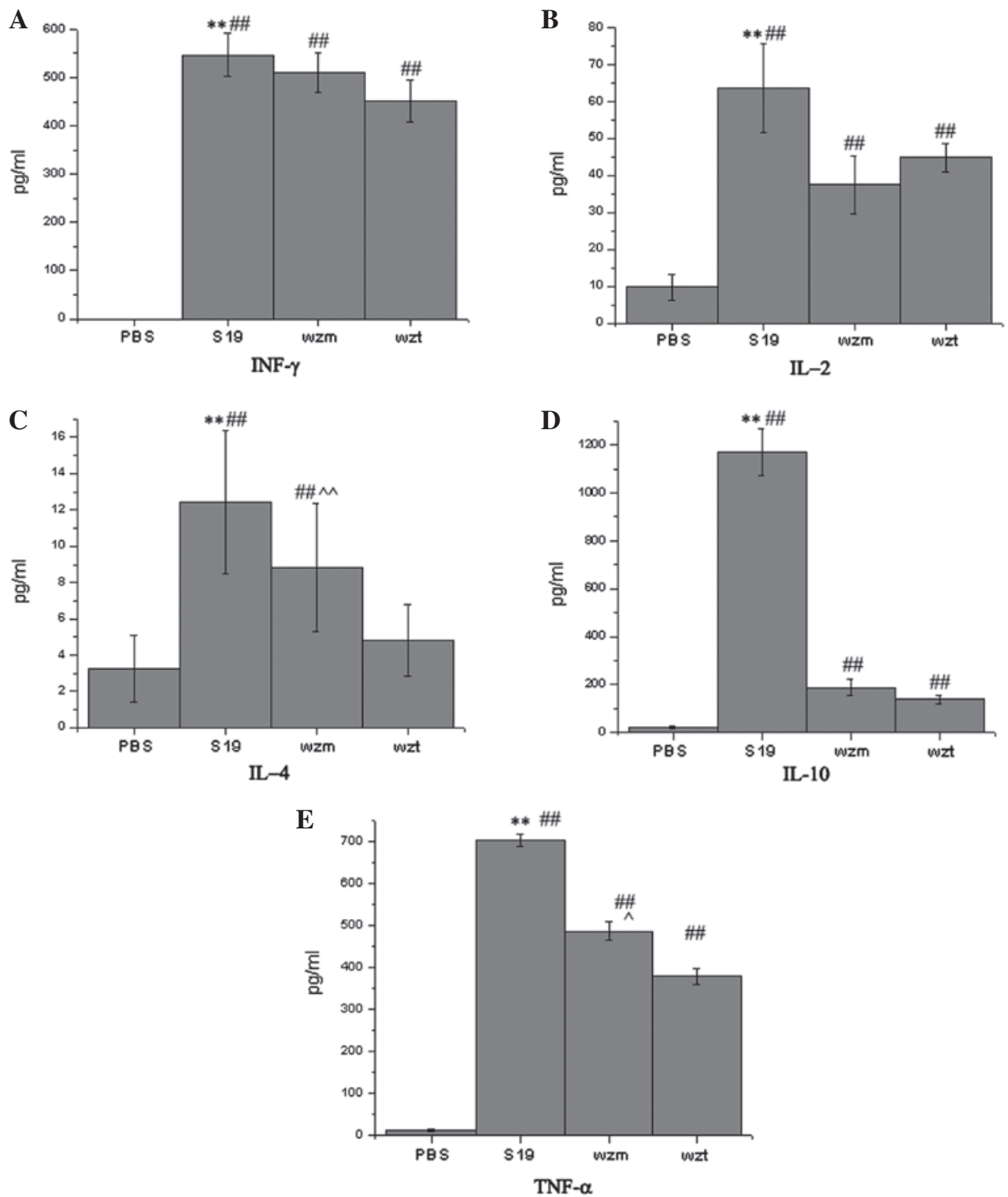

Figure 5. Cytokine concentrations of (A) INF- $\gamma$, (B) IL-2, (C) IL-4, (D) IL-10 and (E) TNF $\alpha$ (n=5). ${ }^{* *} \mathrm{P}<0.01$ compared with $\Delta w z m$ and $\Delta w z t$, respectively;

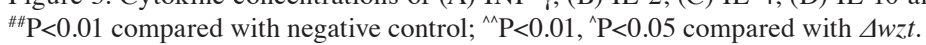



Figure 6. Changes of INF- $\gamma$ levels of S19, $\Delta w z m$ and $\Delta w z t$ mutants in serum $(\mathrm{n}=5) .{ }^{* *} \mathrm{P}<0.01$ compared with $\Delta w z t$ mutants group. in low quantities and IL-4 was detected at very low levels. IL-10 levels induced by S19 were significantly higher than those induced by the rough mutants, while IL-10 levels induced by the wzm mutant were higher than those of the wzt mutant.

Secretion of the inflammatory molecule TNF- $\alpha$ was reduced by rough mutants although not significantly as compared to S19. LPS is considered to be the most important modulator of TNF- $\alpha$ that is required for host defense against intracellular pathogens $(30,31)$. The results showed that the disruption of LPS caused a reduction in TNF- $\alpha$ levels and spleen weights, and the spleen kinetics caused by rough mutants were significantly lower than those of the S19 strain. The TNF- $\alpha$ levels induced by the $\Delta w z t$ mutant were lower than those induced by the $\Delta w z m$ mutant.

These data indicate that the wzt gene may affect the host immune response indirectly. As previously reported, the $w z m$ mutant provides efficient protection against Brucella invasion compared with mutants (25). Wzt disruption may affect the 
expression of more genes associated with the induction of immunity.

\section{Acknowledgements}

This study was funded by a project supported by the National Science and Technology Ministry (2010BAD04B03) and the Key Project of Chinese National Programs for Fundamental Research and Development (No. 2012CB722501).

\section{References}

1. Cardoso PG, Macedo GC, Azevedo V and Oliveira SC: Brucella spp noncanonical LPS: structure, biosynthesis and interaction with host immune system. Microb Cell Fact 5: 13, 2006.

2. Rambow-Larsen AA, Petersen EM, Gourley CR and Splitter GA: Brucella regulators: self-control in hostil environment. Trends Microbiol 17: 371-377, 2009.

3. Al-Tawfiq JA: Therapeutic options for human brucellosis. Expert Rev Anti Infect Ther 6: 109-120, 2008.

4. Pappas G, Papadimitrious P, Akritidis N, Christou L and Tsianos E: The new global map of human brucellosis. Lancet Infect Dis 6: 91-99, 2006.

5. Ficht TA, Kahl-McDonagh MM, Arenas-Gamboa AM and Rice-Ficht AC: Brucellosis: the case for live, attenuated vaccines. Vaccine 27: D40-D43, 2009.

6. Spink WW, Hall JW, Finstad J and Mallet E: Immunization with viable Brucella organisms. Results of a safety test in humans. B World Health Organ 26: 409-419, 1962.

7. Perkins SD, Smither SJ and Atkins HS: Towards a Brucella vaccine for humans. FEMS Microbiol Rev 34: 379-394, 2010

8. Monreal D, Grilló MJ, González D, Marín CM, De Miguel MJ, López-Goni I, Blasco JM, Cloeckaert A and Moriyón I: Characterization of Brucella abortus O-polysaccharide and core lipopolysaccharide mutant and demonstration that a complete core is required for rough vaccines to be efficient against Brucella abortus and Brucella ovis in the mouse model. Infect Immun 71: 3261-3271, 2003.

9. Fugier E, Pappas G and Gorvel JP: Virulence factors in brucellosis: implications for aetiopathogenesis and treatment Expert Rev Mol Med 9: 1-10, 2007.

10. Bundle DR, Cherwonogrodzky JW, Gidney MA, Meikle PJ, Perry MB and Peters T: Definition of Brucella A and M epitopes by monoclonal typing reagents and synthetic oligosaccharides. Infect Immun 57: 2829-2836, 1989.

11. Weynants V, Gilson D, Cloeckaert A, Tibor A, Denoel PA, Godfroid F, Limet JN and Letesson JJ: Characterization of smooth lipopolysaccharides and O-polysaccharides of Brucella species by competition binding assays with monoclonal antibodies. Infect Immun 65: 1939-1943, 1997.

12. Ugalde JE, Comerci DJ, Leguizamón MS and Ugalde RA: Evaluation of Brucella abortus phosphoglucomutase (pgm) mutant as a new live rough-phenotype vaccine. Infect Immun 71: 6264-6269, 2003.

13. Lapaque N, Moriyon I, Moreno E and Gorvel JP: Brucella lipopolysaccharide acts as a virulence factor. Curr Opin Microbiol 8: 60-66, 2005.

14. Eisenschenk FC, Houle JJ and Hoffmann EM: Serum sensitivity of field isolates and laboratory strains of Brucella abortus. Am J Vet Res 56: 1592-1598, 1995

15. Velasco J, Bengoechae JA, Brandenberg K, Lindner B, Seydel U, Gonzalez D, Zahringer U, Moreno E and Moriyon I: Brucella abortus and its closest phylogenetic relative, ochrobacterum spp, differ in outer membrane permeability and cationic peptide resistance. Infect Immun 68: 3210-3218, 2000.
16. Lapaque N, Forquet F, de Chastellier C, Mishal Z, Jolly G, Moreno E, Moriyon I, Heuser JE, He HT and Gorvel JP: Characterization of Brucella abortus lipopolysaccharide macrodomains as mega rafts. Cell Microbiol 8: 197-206, 2006.

17. Porte F, Naroeni A, Ouahrani-Bettache S and Liautard JP: Role of the Brucella suis lipopolysaccharide $\mathrm{O}$ antigen in phagosomal genesis and in inhibition of phagosome-lysosome fusion in murine macrophages. Infect Immun 74: 1481-1490, 2003.

18. Fernandez-Prada CM, Zelazowska EB, Nikolich M, Hadfield TL, Roop RM, Robertson GL and Hoover DL: Interactions between Brucella melitensis and human phagocytes: bacterial surface $\mathrm{O}$-polysaccharide inhibits phagocytosis, bacterial killing and subsequent host cell apoptosis. Infect Immun 71: 2110-2119, 2003.

19. Jiménez de Bagüiés MP, Terraza A, Gross A and Dornand J: Different responses of macrophages to smooth and rough Brucella spp.: relationship to virulence. Infect Immun 72: 2429-2433, 2004

20. Moriyón I, Grilló MJ, Monreal D, González D, Marín C, López-Goñi I, Mainar-Jaime RC, Moreno E and Blasco JM: Rough vaccines in animals brucellosis: structural and genetic basis and present status. Vet Res 35: 1-38, 2004.

21. Adone R, Ciuchini F, Marianelli C, Tarantino M, Pistoia C, Marcon G, Petrucci P, Francia M, Riccardi G and Pasquali P: Protective properties of rifampin-resistant rough mutants of Brucella melitensis. Infect Immun 73: 4198-4204, 2005.

22. Haag AF, Myka KK, Arnold MF, Caro-Hernández $\mathrm{P}$ and Ferguson GP: Importance of lipopolysaccharide and cyclic $\beta-1,2$-glucans in Brucella-mammalian infections. Int J Microbiol 2010: 124509, 2010.

23. Cloeckaert A, Grayon M, Verger JM, Letesson JJ and Godfroid F: Conservation of seven genes involved in the biosynthesis of the lipopolysaccharide O-side chain in Brucella spp. Res Microbiol 151: 209-216, 2000.

24. Godfroid F, Cloeckaert A, Taminiau B, Danese I, Tibor A, de Bolle X, Mertens P and Letesson JJ: Genetic organization of the lipopolysaccharide $\mathrm{O}$-antigen biosynthesis region of Brucella melitensis 16M (wbk). Res Microbiol 151: 655-668, 2000.

25. González D, Grilló MJ, De Miguel MJ, Ali T, Arce-Gorvel V, Delrue RM, Conde-Alvarez R, Muñoz P, López-Goñi I, Iriarte M, Marín CM, Weintraub A, Widmalm G, Zygmunt M, Letesson JJ, Gorvel JP, Blasco JM and Moriyón I: Brucellosis vaccines: assessment of Brucella melitensis lipopolysaccharide rough mutants defective in core and O-polysaccharide synthesis and export. PLoS One 3: e2760, 2008.

26. Allen CA, Adams LG and Ficht TA: Transposon-derived Brucella abortus rough mutants are attenuated and exhibit reduced intracellular survival. Infect Immun 66: 1008-1016, 1998.

27. Ried JL and Collmer A: An nptI-sacB-sacR cartridge for constructing directed, unmarked mutations in gram-negative bacteria by marker exchange-eviction mutagenesis. Gene 57 : 239-246, 1987.

28. Christian RHR and Chris W: Lipopolysaccharide endotoxins. Annu Rev Biochem 71: 635-700, 2002.

29. Grilló MJ, Blasco JM, Gorvel JP, Moriyón I and Moreno E: What have we learned from brucellosis in the mouse model? Vet Res 43: 29, 2012

30. Skyberg JA, Thornburg T, Rollins M, Huarte E, Jutila MA and Pascual DW: Murine and bovine $\gamma \delta$ T cells enhance innate immunity against Brucella abortus infections. PLoS One 6: e21978, 2012

31. Li X and He Y: Caspase-2-dependent dendritic cell death, maturation and priming of $\mathrm{t}$ cells in response to Brucella abortus infection. PLoS One 7: e43512, 2012. 